Article

\title{
Sex-Specific Habitat Suitability Modeling for Panthera tigris in Chitwan National Park, Nepal: Broader Conservation Implications
}

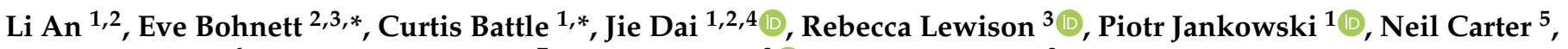 \\ Dirgha Ghimire ${ }^{6}$, Maheshwar Dhakal ${ }^{7}$, Jhamak Karki ${ }^{8}$ (i) and Alex Zvoleff ${ }^{9}$
}

1 Department of Geography, San Diego State University, San Diego, CA 92182, USA; lan@sdsu.edu (L.A.); jdai@sdsu.edu (J.D.); pjankows@sdsu.edu (P.J.)

2 Center for Complex Human-Environment Systems, San Diego State University, San Diego, CA 92182, USA

3 Department of Biology, San Diego State University, San Diego, CA 92182, USA; rlewison@sdsu.edu

4 Department of Geography, University of California, Santa Barbara, CA 93106, USA

5 School for Environment and Sustainability, University of Michigan, Ann Arbor, MI 48109, USA; nhcarter@umich.edu

6 Institute for Social Research, University of Michigan, Ann Arbor, MI 48106, USA; nepdjg@umich.edu

7 Biodiversity and Environment Division, Ministry of Forests and Soil Conservation, Kathmandu 44600, Nepal; maheshwar.dhakal@gmail.com

8 Kathmandu Forestry College, Kathmandu 44600, Nepal; jbkarki@gmail.com

9 Conservational International, Arlington, VA 22202, USA; azvoleff@outlook.com

* Correspondence: ebohnett@sdsu.edu (E.B.); csbattle@gmail.com (C.B.)

\section{check for} updates

Citation: An, L.; Bohnett, E.; Battle, C.; Dai, J.; Lewison, R.; Jankowski, P.; Carter, N.; Ghimire, D.; Dhakal, M.; Karki, J.; et al. Sex-Specific Habitat Suitability Modeling for Panthera tigris in Chitwan National Park, Nepal: Broader Conservation Implications. Sustainability 2021, 13, 13885. https://doi.org/10.3390/ su132413885

Academic Editor: Reuven Yosef

Received: 22 November 2021 Accepted: 13 December 2021 Published: 15 December 2021

Publisher's Note: MDPI stays neutral with regard to jurisdictional claims in published maps and institutional affiliations.

Copyright: (c) 2021 by the authors. Licensee MDPI, Basel, Switzerland. This article is an open access article distributed under the terms and conditions of the Creative Commons Attribution (CC BY) license (https:/ / creativecommons.org/licenses/by/ $4.0 /)$.

\begin{abstract}
Although research on wildlife species across taxa has shown that males and females may differentially select habitat, sex-specific habitat suitability models for endangered species are uncommon. We developed sex-specific models for Bengal tigers (Panthera tigris) based on camera trapping data collected from 20 January to 22 March 2010 within Chitwan National Park, Nepal, and its buffer zone. We compared these to a sex-indiscriminate habitat suitability model to assess the benefits of a sex-specific approach to habitat suitability modeling. Our sex-specific models produced more informative and detailed habitat suitability maps and highlighted vital differences in the spatial distribution of suitable habitats for males and females, specific associations with different vegetation types, and habitat use near human settlements. Improving and refining habitat models for this and other critically endangered species provides the necessary information to meet established conservation goals and population recovery targets.
\end{abstract}

Keywords: sex-specific modeling; species distribution model; tiger conservation

\section{Introduction}

The accelerated pace of human development and land-use change, overexploitation of natural capital, and environmental degradation have caused a loss of terrestrial mammal habitat quality during the past two centuries, especially for sizeable terrestrial carnivore species [1-5]. These large-bodied, wide-ranging carnivores are often at the top of food webs, with low abundances due to their high metabolic demands and requiring high prey abundance and expansive habitats for persistence. Large predators are also more sensitive to human-induced climate change, habitat loss, and fragmentation than smaller, less wideranging species [6]. As a result, human-induced habitat loss and degradation, along with direct persecution or harvest and depletion of prey, have given rise to a massive decline in large carnivore population size and geographic range worldwide, jeopardizing the enormous economic and ecosystem services they deliver to humans such as maintaining mammal, avian, invertebrate, and herpetofauna abundance [7].

Tigers (Panthera tigris) are an iconic species, among the 31 largest mammalian carnivores considered globally important [8]. Currently, tigers inhabit less than $7 \%$ of their historical geographic range, and fewer than 4000 animals live in the wild [9]. Despite 
numerous long-standing tiger conservation initiatives, $41 \%$ of this range contraction occurred between 1996 and 2006 [10]. Range limitations are due primarily to human activities, including land cover conversions to human land uses and development. Prey depletion, likely due to human hunting and illegal killing, is pervasive and has led to the extirpation of formerly well-established tiger populations from several protected areas. Today, the tigers that remain in the wild are sparsely distributed across the Asian landscape, primarily restricted to a patchy, disconnected network of protected areas. Thus, in the context of global tiger conservation, protecting suitable habitats that can support a large population of breeding tigers is crucial.

Identifying high-quality habitats for tigers requires understanding the many factors that influence habitat use, including demographic characteristics, such as sex. Several studies have identified differences in the selection and distribution of habitats for males and females. For example, studies of black bears (Ursus americanus), brown bears (Ursus arctos), cheetahs (Acinonyx jubatus), Florida panthers (Puma concolor coryi), and jaguars (Panthera onca) have all shown significant sex-mediated differences in preferred vegetation type and density, home range size, and aversion to roads [11-13]. These essential differences are likely due to sexual dimorphism and differences in energy consumption, reproduction, and other life-history attributes. Indeed, in the Russian Far East, adult male tigers must consume a minimum of $5.2 \mathrm{~kg} /$ day, whereas an adult female raising four cubs needs an average of $11.4 \mathrm{~kg} /$ day over the reproduction period. To capture some of these sexbased differences in habitat selection, Carter et al. (2015) used an agent-based model to simulate tiger population dynamics in Chitwan National Park (CNP), Nepal, with female tigers developing exclusive territories based on prey abundances, while males established exclusive territories overlapping those of multiple females [14,15]. Most models of tiger habitat suitability, however, pool male and female occurrences, potentially obscuring sexspecific information about habitat selection and mischaracterizing habitat suitability across landscapes [16-18]. Consequently, land managers may implement ineffective or counterproductive tiger conservation interventions as strategies to protect specific habitats based on sex-indiscriminate models that may not adequately incorporate the habitat requirements of breeding females, the population's fundamental reproductive unit.

Here, we develop sex-specific habitat suitability models using camera trapping data collected within and adjacent to CNP to determine how male and female tiger habitats are distributed, identify what factors influence their distributions, and determine to what degree habitat distributions of male and female tigers differ. We also test a sex-indeterminate model for all tiger occurrences and compare the results to the sex-specific models. CNP is the focus of our efforts as it is home to approximately three-quarters of Nepal's protected wild tiger population and is one of only 28 reserves in the world that can support more than 25 breeding female tigers [19]. CNP is also a fundamental part of the local economy for over 200,000 people who live in the Chitwan Valley [20]. Many residents rely on the natural resources within or adjacent to CNP to supplement their income and livelihood materials $[20,21]$. Human activities in and around CNP likely affect tiger habitat quality [22]. Although the analysis focuses on CNP, the methodological tools and techniques we present can serve as a template for assessing sex-specific habitat suitability for large carnivore species, including tigers, throughout their range. Information on sex-specific habitat suitability can be combined with other data on demographic dynamics, such as age-class composition and change over time, to better tailor conservation actions.

\section{Data and Methods}

\subsection{Study Area}

Established in 1973 as Nepal's first national park, CNP (roughly $1200 \mathrm{~km}^{2}$ ) lies between the Churia and Mahabharat Ranges and has a tropical climate, with a mean annual rainfall of over $2100 \mathrm{~mm}$ [23]. Sal forest (Shorea robusta) covers approximately $73 \%$ of the park, followed by $12 \%$ grassland, $8 \%$ riverine forest, and $3 \%$ water [24]. Today CNP is a United Nations Educational, Scientific, and Cultural Organisation (UNESCO) World Heritage 
Site and constitutes the core of the Terai Arc Landscape (TAL) - a crescent-shaped area of approximately 12.5 million acres which lies along the border of India and Nepal [21]. This landscape includes 15 fragmented protected areas, which support some of the world's highest tiger densities [25]. Importantly, our study site also includes a portion of the surrounding buffer zone forests, established in 1996 and managed by local user groups that decide when forest resources may be extracted, and how much (Figure 1).

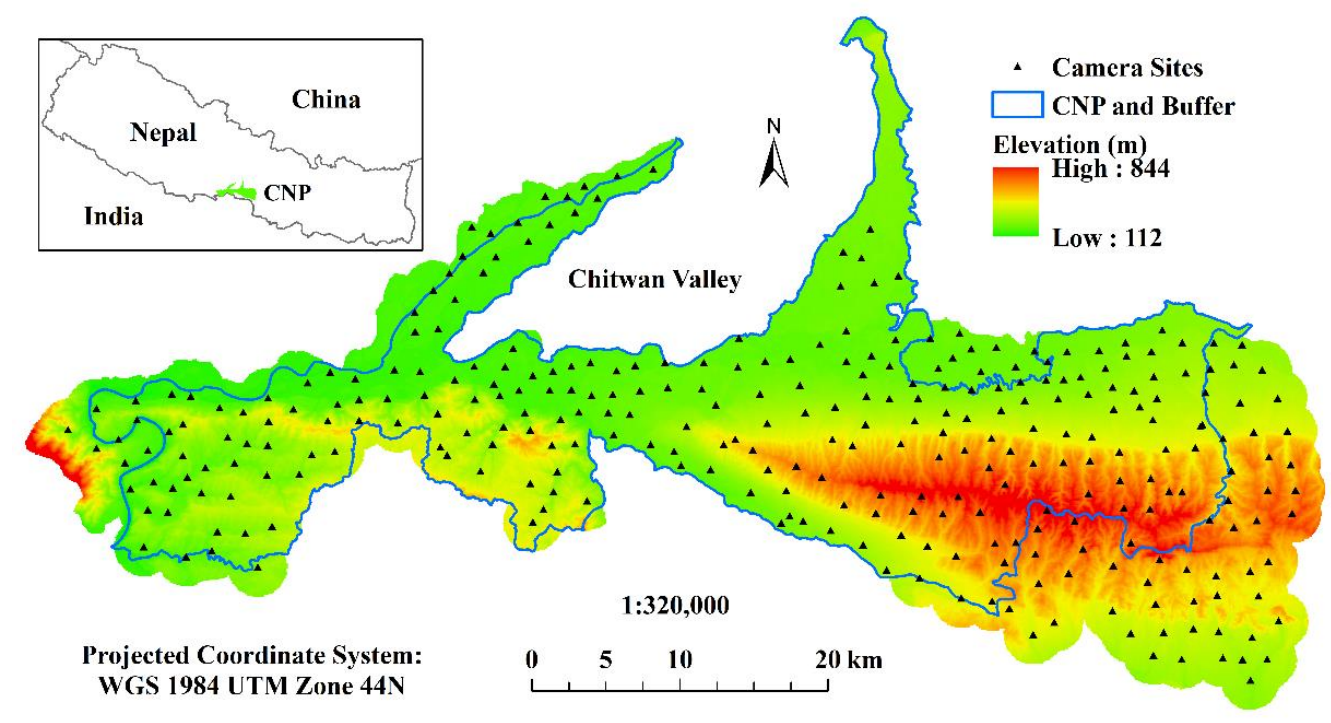

Figure 1. Study area and camera trapping locations.

From 20 January to 22 March 2010, surveys to assess the distribution and number of tigers and their prey used 310 camera traps (Figure 1). The trap sampling design sought to minimize spatial bias and maximize the number of tiger images captured, using knowledge from previous field survey data on tiger movements and signs. Researchers placed the cameras along park roads, fire-lines, river and stream beds, ridge tops, and animal trails between 1.5 and 2 kilometers apart. The cameras operated for 4793 trap nights (i.e., cumulative nights). From 344 tiger photographs, 62 individuals were identified, including 15 males with 95 total detections, 41 females with 164 total detections, and six unidentified sub-adults [26]. We were able to identify female tigers in 69 camera locations and males in 57 locations, and in general, 108 of the 310 camera traps detected at least one tiger.

\subsection{Variable Generation and Selection}

Mazak (1997) identified a suite of important tiger habitat variables, including vegetation type and density, prey abundance, and distance to water. We included these variables in our analysis. In addition, we included elevation and distance to human settlements as potential predictor variables, which we will justify later.

A land cover map for the entire study area was necessary to measure tiger distribution response to vegetation type and density. The unsupervised classification algorithm ISODATA in Erdas Imagine 2014 generated the land cover map. Two cloud-free, 30-m resolution Landsat 8 images from March 2015 created a composite image consisting of the blue, green, and red spectral bands and the normalized difference vegetation index (NDVI). For each image, the algorithm classified the landscape into five categories: Sal forest, riverine forest, grassland, water, and exposed soil [24]. We used 2015 imagery for several reasons: (1) there was no full coverage, (2) imagery often had a large percent of cloud coverage, and (3) there was a "scan line" issue, where 2015 was the closest date we could get full coverage of the study area. Accuracy assessments compared a random stratified sample of 150 points to similar vegetation classifications for the study area in the same period and earlier from high-resolution imagery $[17,24]$. In addition, ground reference data included vegetation types recorded at each camera trap. The accuracy assessment did not include 
locations that lacked confidence in accuracy. In total, 428 accuracy assessment locations yielded an overall accuracy of $88 \%$. From this classification, focal statistics describing the percent cover of each vegetation type within a 400-meter distance from water features and human settlements were derived for every cell in the study area using ArcGIS 10.2. We chose 400 meters because long-term radio telemetry studies within CNP have established that tigers actively search for prey within a radius of 400 meters [27].

Prey abundance is vital for the survival of large carnivores such as tigers, and large mammalian prey found in our study site include chital (Axis axis), sambar (Rusa unicolor), wild boar (Sus scrofa), and gaur (Bos gaurus) $[26,28,29]$. Prey abundances for this research were derived from the camera data using Empirical Bayesian Kriging (EBK) in ArcGIS 10.2 at the same 30-meter resolution of our land cover classification. EBK is an interpolation method that uses data subsetting and repeated simulations to account for data non-stationarity and estimate uncertainty in the final semivariogram.

Multicollinearity tests sought to identify highly correlated predictor variables. The two most highly correlated variables were the percent cover of Sal forest and percent cover of grassland $(\mathrm{r}=-0.7$; Table 1$)$. When tested against each group individually, models including the percent cover of Sal forest performed best without its highly correlated partner, the percent cover of grassland. Therefore, our final models excluded the percent cover of grassland. Both distance to human-disturbed areas and distance to water highly correlated with elevation $(r=0.66$ and 0.64 , respectively). As the range of elevations within our study site $(112-844 \mathrm{~m})$ is well within the range of elevations that tigers are known to inhabit and prefer in Nepal $(<2000 \mathrm{~m}$ and $<1500 \mathrm{~m}$ respectively [30], then all of our final models excluded elevation. The last suite of predictor variables included in our models was prey abundance, percent cover of Sal forest, percent cover of riverine forest, distance to water, and distance to human settlements.

Table 1. Correlation matrix for potential predictor variables (Pearson's $\mathrm{r}$ with a $p$-value in parentheses).

\begin{tabular}{|c|c|c|c|c|c|c|c|}
\hline & $\begin{array}{l}\text { Dist. to } \\
\text { Water }\end{array}$ & $\begin{array}{l}\text { Dist. to } \\
\text { Human }\end{array}$ & Prey & Elevation & $\begin{array}{c}\% \\
\text { Grass }\end{array}$ & $\begin{array}{c}\% \\
\text { Riverine }\end{array}$ & $\begin{array}{c}\% \\
\text { Sal }\end{array}$ \\
\hline $\begin{array}{l}\text { Dist. to } \\
\text { Water }\end{array}$ & 1 & $\begin{array}{c}0.5241 \\
\left(2.2 \times 10^{-16}\right) \\
\end{array}$ & $\begin{array}{l}-0.1143 \\
(0.0443)\end{array}$ & $\begin{array}{c}0.6498 \\
\left(2.2 \times 10^{-16}\right)\end{array}$ & $\begin{array}{c}-0.3731 \\
\left(1.12 \times 10^{-11}\right)\end{array}$ & $\begin{array}{c}-0.3068 \\
\left(3.49 \times 10^{-8}\right)\end{array}$ & $\begin{array}{c}0.5527 \\
\left(2.2 \times 10^{-16}\right) \\
\end{array}$ \\
\hline $\begin{array}{l}\text { Dist. to } \\
\text { Human }\end{array}$ & & 1 & $\begin{array}{l}-0.2085 \\
(0.0002)\end{array}$ & $\begin{array}{c}0.6694 \\
\left(2.2 \times 10^{-16}\right) \\
\end{array}$ & $\begin{array}{c}-0.3320 \\
\left(2.04 \times 10^{-9}\right)\end{array}$ & $\begin{array}{c}-0.3310 \\
\left(2.3 \times 10^{-9}\right)\end{array}$ & $\begin{array}{c}0.5152 \\
\left(2.2 \times 10^{-16}\right)\end{array}$ \\
\hline Prey & & & 1 & $\begin{array}{l}-0.1321 \\
(0.0210)\end{array}$ & $\begin{array}{c}0.3767 \\
\left(6.8 \times 10^{-12}\right) \\
\end{array}$ & $\begin{array}{c}0.1297 \\
(0.0223) \\
\end{array}$ & $\begin{array}{c}-0.3447 \\
\left(4.44 \times 10^{-10}\right)\end{array}$ \\
\hline Elevation & & & & 1 & $\begin{array}{c}-0.3310 \\
\left(3.19 \times 10^{-9}\right)\end{array}$ & $\begin{array}{c}-0.2877 \\
\left(3.17 \times 10^{-7}\right)\end{array}$ & $\begin{array}{c}0.4819 \\
\left(2.2 \times 10^{-16}\right)\end{array}$ \\
\hline$\%$ Grass & & & & & 1 & $\begin{array}{l}-0.0269 \\
(0.6359)\end{array}$ & $\begin{array}{c}-0.7085 \\
\left(2.2 \times 10^{-16}\right)\end{array}$ \\
\hline$\%$ Riverine & & & & & & 1 & $\begin{array}{c}-0.5686 \\
\left(2.2 \times 10^{-16}\right)\end{array}$ \\
\hline$\%$ Sal & & & & & & & 1 \\
\hline
\end{tabular}

\subsection{Statistical Modeling}

We used two analytical frameworks to identify sex-specific habitats for tigers in CNP, maximum entropy (Maxent) [31] and Bayesian occupancy modeling frameworks [32]. These models aimed to study the habitat selection variability and differences within the protected area between males and females and shed light on the differences between the two modeling techniques.

\subsubsection{Maxent}

Maxent is a general-purpose modeling software designed to work with presence-only data. It models habitat suitability for a species by estimating the target probability distribution with maximum entropy, subject to certain constraint variables, such as sunlight and water availability. Of all possible probability distributions that meet these constraints, 
Maxent chooses the most spread out distribution, that is, the closest to a uniform distribution $[31,33,34]$. In numerous studies, Maxent has shown equal or superior predictive accuracy than other presence-only modeling methods [35-37].

Accepting Maxent's default settings risks creating over-parameterized and overfitting models. We adjusted the regularization multiplier (RM) to estimate response curves for environmental predictors to address this issue. Increasing the RM helps to create smoother, more ecologically realistic responses. However, as RM increases, curves become over smoothed, and model accuracy measures are negatively affected. To find the optimal RM; we used a method developed by Warren (2012) to generate Akaike's Information Criterion (AIC) for models with varying RM. After selecting the final group of predictors, we ran each model using RMs between 1 and 20 and assessed model AIC. In all cases, Maxent's default settings produced more than twice as many parameters, as well as higher AIC values, when compared to our final models.

\section{Model Evaluation}

AUC, however, presents concerns regarding presence-only data. When there is no absence data, the axis representing the rate of false positives is replaced by the proportion of area predicted as present. As a result, by increasing the study area's geographic extent (i.e., including an increasingly heterogeneous environmental background) modelers can increase the rate of correctly predicted absences, artificially inflating AUC scores [38]. Hence, AUC is greatly affected by how widespread a species is within the study area, which is one explanation for why rare species restricted to a smaller subset of environmental variables across their range tend to have higher AUC scores than widespread species [36,39]. To address this potential bias, we supplemented the use of AUC as a model evaluation statistic by comparing our models to a null model for significance testing [40]. A total of 1000 random distributions of 57, 69, and 108 points (equal to the number of males, females, and sex-indiscriminate occurrence locations, respectively) were generated within the study area. Each random distribution was modeled using the same parameters as its corresponding true data model (Table 2). Afterward, the resulting AUCs were compared to the test AUCs of each true data model. In all cases, the data model's $p$-value compared to its corresponding null model was less than 0.001 , demonstrating that each was highly significant compared to random predictions generated by chance.

Table 2. Statistical significance of true model compared to the random model.

\begin{tabular}{cccccc}
\hline \multirow{2}{*}{ Female } & & $n$ & Avg. AUC & $\begin{array}{c}\text { Standard } \\
\text { Deviation }\end{array}$ & $p$-Value \\
& True & 69 & 0.7086 & 0.2486 & $2.72 \times 10^{-14}$ \\
\cline { 2 - 6 } Male & Random & 1000 & 0.5143 & 0.2762 & \\
\cline { 2 - 6 } & True & 57 & 0.6692 & 0.2892 & $3.73 \times 10^{-9}$ \\
\cline { 2 - 6 } & Random & 1000 & 0.4984 & 0.2572 & \\
\hline \multirow{2}{*}{ Sex-Indiscriminate } & True & 108 & 0.6885 & 0.2780 & $2.06 \times 10^{-10}$ \\
\cline { 2 - 6 } & Random & 1000 & 0.5041 & 0.2830 & \\
\hline
\end{tabular}

\subsubsection{Occupancy Modelling}

Occupancy modeling involves sampling a location with a given number of sites and determining whether a site is occupied by modeling the presence-absence information [32]. An occupancy model is a hierarchical model that uses joint probability distributions to tackle the problem that species are imperfectly detected. Model assumptions for "independence between sampling sites" create spacing requirements of cameras between sites that are very large for species like tigers, whose home ranges are naturally vast. However, these assumptions can be relaxed to model "use" [41]; therefore, the information can be used for a hierarchical model with the probability of use and probability of detection that 
models the resource selection probability function [17]. The model consists of two logistic regression models, variation in use between sites, and detectability [42]. Observed data consist of a site $(i) \times$ sample $(j)$ matrix of presence/absence data for the entire dataset and for males and females separately. The dependent variable $y_{i j}$ indicates a tiger was detected $\left(y_{i j}=1\right)$ or not detected $\left(y_{i j}=0\right)$ at site $i(1, \ldots, 310$ sites $)$ during survey $j(1, \ldots$; 62 surveys). We describe the observation process (detection) as

$$
y_{i j} \mid z_{i} \sim \operatorname{Bernoulli}\left(z_{i} \times p_{i j}\right) .
$$

The observations are modeled as a product of the $z$-matrix $\left(z_{i}\right)$ for each site $i$ and the detection probability $p_{i j}$, which is the probability of detecting a tiger at site $i$ during survey $j$. Deriving the $z$-matrix is dependent on the ecological processes modeled by the true occupancy $\left(\psi_{i}\right)$ :

$$
z_{i} \sim \operatorname{Bernoulli}\left(\psi_{i}\right)
$$

The model of species response to landscape covariates for occupancy:

$$
\begin{gathered}
\operatorname{logit}\left(\psi_{i}\right)=\beta_{0}+\beta_{1} * \text { covariate }_{1} \ldots+\beta_{k} * \text { covariate }_{k} \\
\operatorname{logit}\left(p_{i j}\right)=\alpha_{k}
\end{gathered}
$$

All occupancy models were fitted in a Bayesian framework using jagsUI in program $\mathrm{R}$ [43]. We used non-informative priors and ran three chains for 5000 iterations, burning 1000 and thinning 100 . The convergence of the models was assessed by having an R-hat of $<1.1$, which is considered to be acceptable in the literature.

\section{Model Evaluation}

Fivefold cross-validation was used to evaluate each model for AUC, log score, and briers log metrics using methods developed by Broms, Hooten, and Fitzpatrick (2016) and fit to a single-species model [44]. AUC is a rank-based rule that gives high scores to probabilities of occurrences and lower scores to absences, similar to the Maxent model except that in this case, our absences are explicit as to locations and days there were no camera trap photos. The survey locations were subset into $40 \%$ training and $60 \%$ testing subsets for each of the five folds. The final scores were averages of the five folds.

\section{Results}

\subsection{Maxent}

For male tigers, the best performing model had a test AUC of 0.67 and included two variables: prey abundance, which was positively associated with male presence and contributed $70 \%$ to Maxent's suitability prediction; and distance to water, which was negatively related to male presence, and contributed $30 \%$. The inclusion of distance to human settlements or any combination of vegetation variables did not improve model performance. This AUC value (0.67), as well as the limited number of influential predictors, suggests male tigers are more widespread within our study area and affirms that male tigers have a more generalized use of habitat [24].

The characterization of male tigers as generalists was also reflected in Maxent's relatively flat suitability surface (Figure 2), with values that ranged from 0.09 to 0.86 (on a scale from 0 to 1$)$. Only about $8 \%$ of the study area $\left(115 \mathrm{~km}^{2}\right)$ fell into the least suitable class (0-0.3; [45]). Moderately suitable (0.3-0.6) habitats accounted for $85 \%$ of the study area $\left(1194 \mathrm{~km}^{2}\right)$, while the suitable (0.6-0.8) and highly suitable $(0.8-1)$ classes accounted for $7 \%$ and less than $1 \%$ of the study area $\left(100 \mathrm{~km}^{2}\right.$, and $\left.1.45 \mathrm{~km}^{2}\right)$, respectively (Table 3$)$. Areas of highest suitability were concentrated in the lowland floodplains, while moderate suitability areas extended to most of the Churia Hills, surrounding small areas of least suitable habitat (Figure 2). 


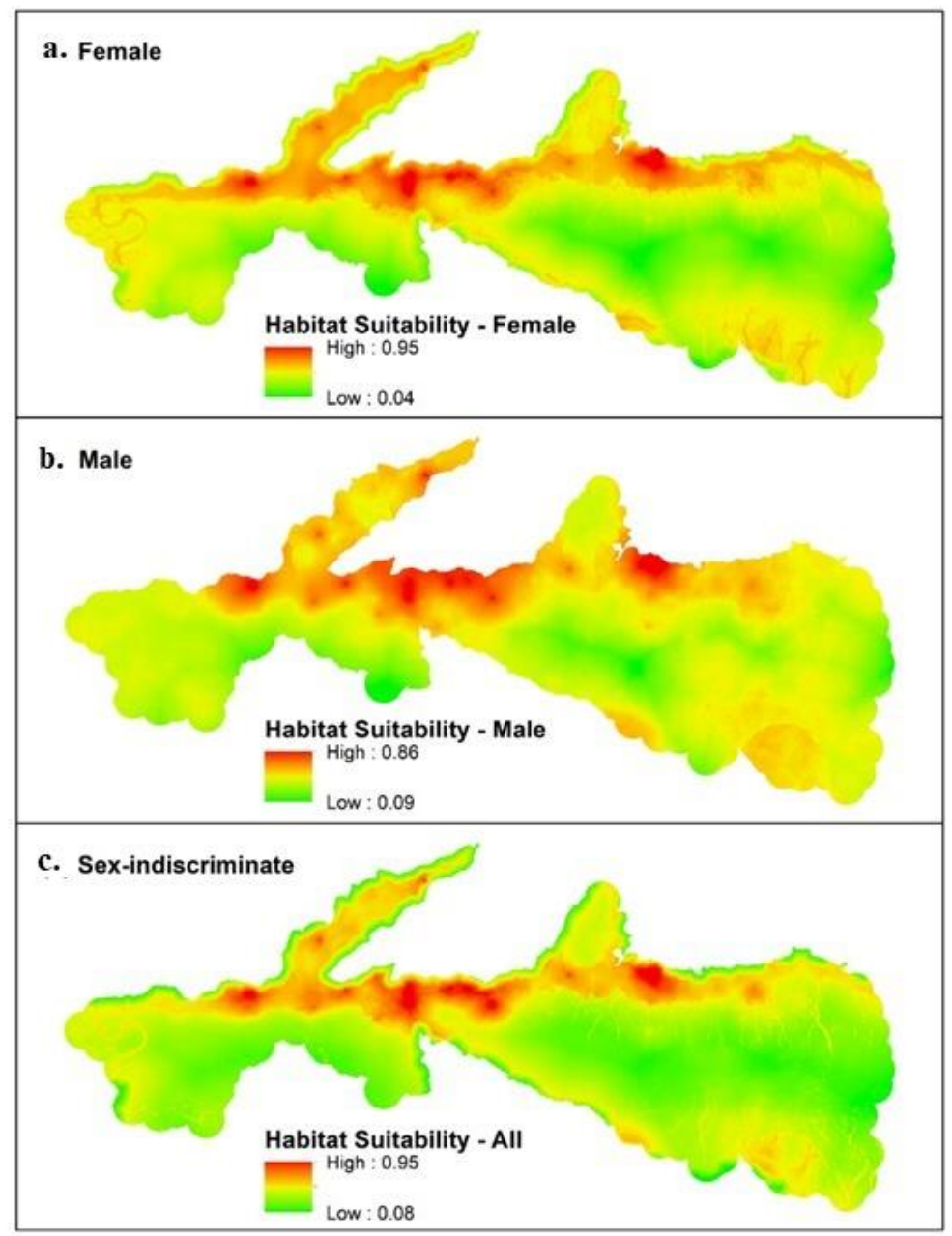

Figure 2. Maxent continuous habitat suitability maps generated by sex-specific models.

Table 3. Percentage and area of suitability classes predicted for each modelled group.

\begin{tabular}{cccccc}
\hline Models & Habitat Suitability & $\mathbf{0 . 0 - 0 . 3}$ & $\mathbf{0 . 3 - 0 . 6}$ & $\mathbf{0 . 6 - 0 . 8}$ & $\mathbf{0 . 8 - 1 . 0}$ \\
\hline \multirow{2}{*}{ Female } & \% of study area & 28.1 & 65.4 & 5.9 & 0.5 \\
\cline { 2 - 5 } & Total area $\left(\mathrm{km}^{2}\right)$ & 396.5 & 921.8 & 83.3 & 7.5 \\
\hline \multirow{2}{*}{ Male } & \% of study area & 8.1 & 84.7 & 7.0 & 0.1 \\
\cline { 2 - 6 } & Total area $\left(\mathrm{km}^{2}\right)$ & 114.6 & 1193.6 & 99.6 & 1.5 \\
\hline \multirow{2}{*}{ Sex-Indiscriminate } & \% of study area & 31.9 & 61.4 & 6.0 & 0.6 \\
\cline { 2 - 5 } & Total area $\left(\mathrm{km}^{2}\right)$ & 449.6 & 865.6 & 85.6 & 8.4 \\
\hline
\end{tabular}

For female tigers, the best performing model had a test AUC of 0.71 and included prey abundance, percent cover of Sal forest, distance to water, and distance to human settlements. The two most influential variables were prey abundance (positively associated) and percent cover of Sal forest (negatively associated), and contributed 35\% and 31\%, respectively, to Maxent's suitability prediction. Distance to water and distance to human settlements contributed $17 \%$ to the model and were negatively associated with female presence. The larger constellation of factors influencing female tiger presence together with the higher AUC values contrasts with our findings for male tigers and supports the hypothesis that female tigers have a more restricted range of suitable habitat [46].

This female distribution showed significant differences from our male model (Figure 2). The suitability scores varied from 0.03 to $0.94,15 \%$ greater than males. Most suitable habi- 
tats (with suitability scores between 0.3 and 1) for female tigers were also ideal for males, while habitats only suitable for female tigers were rare and hard to capture (Figure 3). Areas of suitable habitat were centered on the same floodplain locations, but included significantly less area in the Churia Hills (Figure 3). The lowest suitability class covered nearly $28 \%$ of the study area $\left(396.5 \mathrm{~km}^{2}\right)$. The most highly suitable areas $(0.8-1)$ had higher scores and were more extensive in area, at $7.5 \mathrm{~km}^{2}$ (compared to $1.5 \mathrm{~km}^{2}$ for males). Moderately suitable and suitable habitats covered $65.4 \%$ and $5.9 \%$ of the study area $\left(921.8 \mathrm{~km}^{2}\right.$ and $83.3 \mathrm{~km}^{2}$ ), respectively (Table 3; Figure 2).

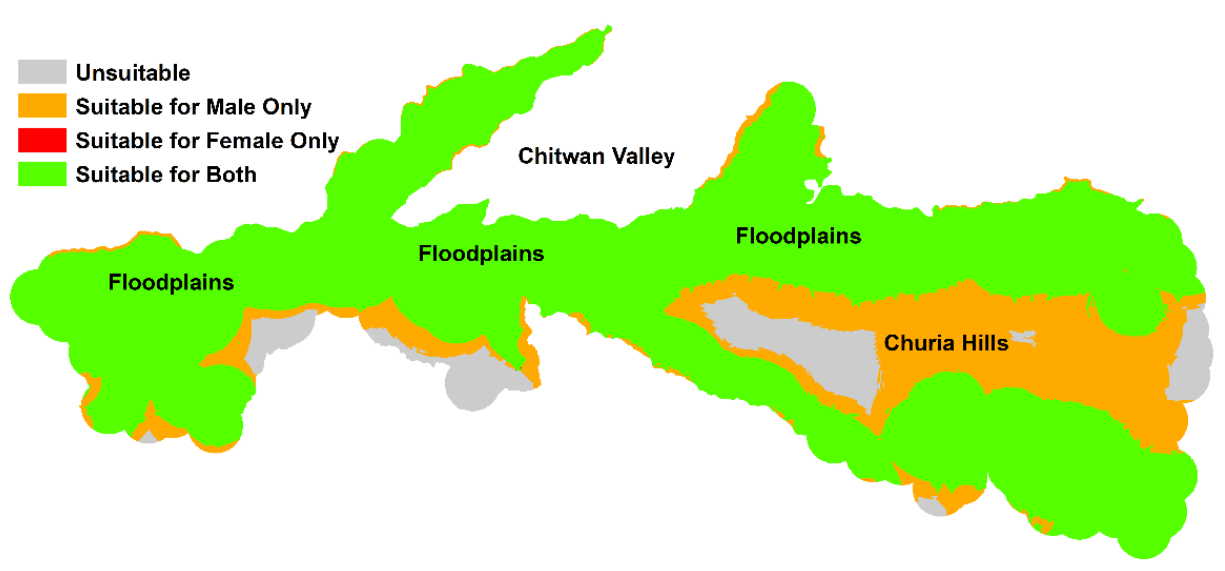

Figure 3. Binary suitable habitat map for tigers in our study area (with suitability between 0.3 and 1).

Our best performing sex-indiscriminate model had a test AUC of 0.69. Prey abundance proved to be the most critical variable, contributing $43 \%$ to the prediction. Overall, this model was similar to our female model, with percent cover of Sal forest contributing 27\%, distance to human settlements $24 \%$, and distance to water $6 \%$. Other than prey availability, all predictors were negatively associated with suitability.

\subsection{Occupancy}

The tiger occupancy model estimates $80 \%$ occupancy for the Chitwan National Park area, with males occupying $50 \%$ and females $41 \%$ of the sampled area. The map estimates reveal a slightly more restricted area which the female tigers inhabit (see Figure 4).

The male, female, and sex-indiscriminant model coefficients show that the only landscape covariate with a consistently positive response between models was higher prey density (Table 4). All models showed a negative coefficient for urban proximity and percent Sal forest. The sex-indiscriminate models show that tigers prefer closer proximity to water within riverine areas, higher prey densities, areas closer to settlements, and a low percentage of Sal forest areas. Males had a positive coefficient for preferring riverine areas compared to females.

Table 4. Occupancy model coefficients for the landscape variables.

\begin{tabular}{cccc}
\hline & Female & Male & Sex-Indiscriminate \\
\hline Urban & -0.336 & -0.900 & -0.760 \\
\hline Sal Forest & -0.175 & -1.594 & -1.087 \\
\hline River & -0.023 & 0.480 & 0.221 \\
\hline Distance to Water & -0.130 & -0.213 & 0.015 \\
\hline Prey Density & 1.588 & 0.949 & 1.572 \\
\hline
\end{tabular}




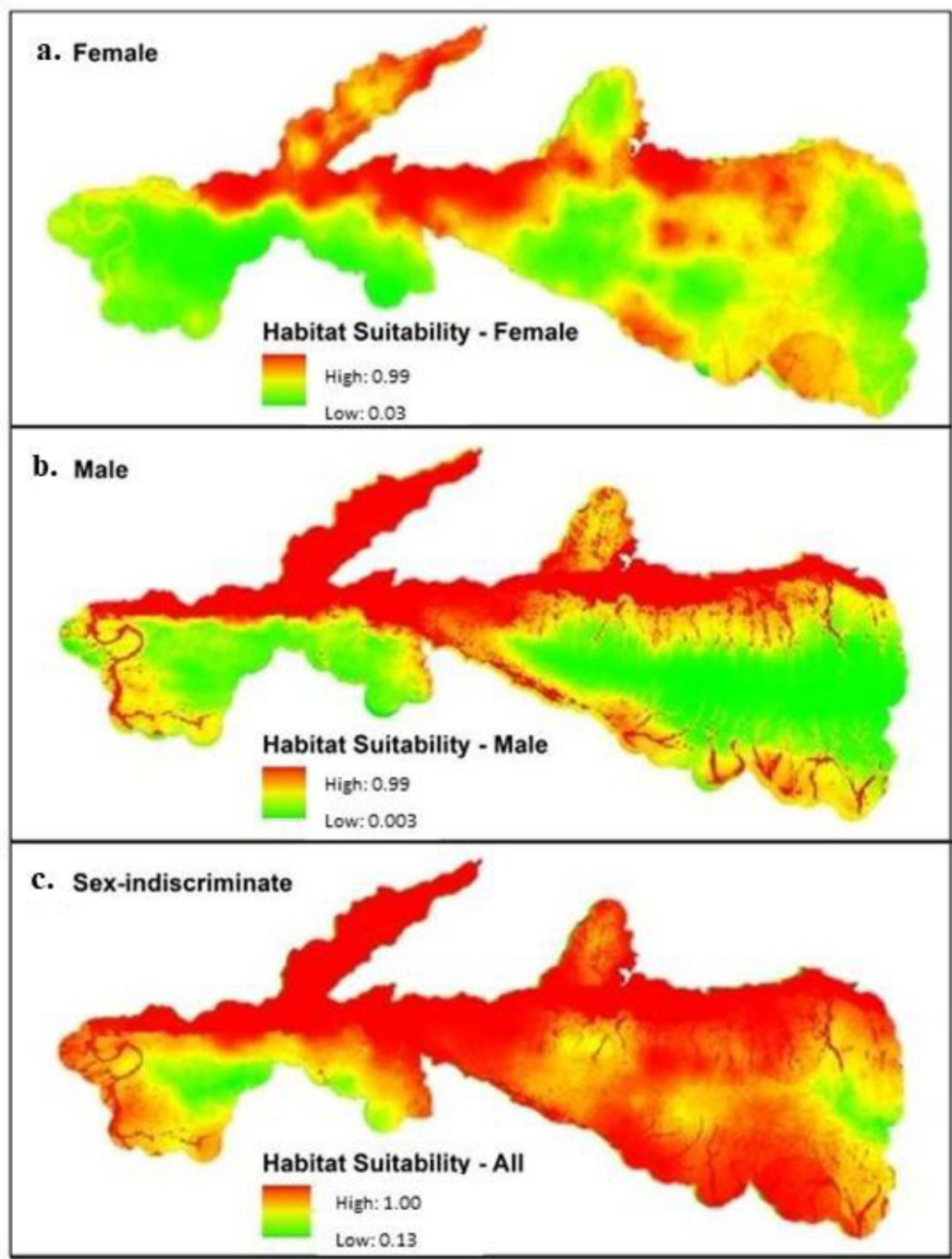

Figure 4. Bayesian occupancy continuous habitat suitability maps generated by sex-specific models.

The model evaluation results from the occupancy modeling were similar to the Maxent model. The female model performed the best, with AUC 0.75, followed by the model for the males with AUC 0.69 and finally the full model with AUC 0.63; the log and Briers log showed similar fitting metrics (Table 5).

Table 5. Model evaluation metrics for the Bayesian occupancy model, including log score, AUC, and Briers log for each of the three models (female, male, and full).

\begin{tabular}{cccc}
\hline & Log Score & AUC & Briers Log \\
\hline Female & 229.72 & 0.75 & 17.33 \\
\hline Male & 307.35 & 0.69 & 24.28 \\
\hline Sex-Indiscriminate & 482.03 & 0.63 & 47.64 \\
\hline
\end{tabular}

\section{Discussion}

As range contraction and population declines continue, the need for robust suitability models for tigers intensifies. Our sex-specific habitat models provided critical information that the sex-indiscriminate model did not. CNP floodplains included prime habitats for both males and females; for females, habitat suitability was primarily restricted to this area and was significantly higher than that for males. Additionally, while male distribution was 
driven solely by prey and water availability, females exhibited an aversion to Sal forest and human settlements for a set of potential reasons to be discussed later.

Differences in the geographic distribution of suitable habitats between sexes are likely the result of different reproductive strategies. Males do not aid in rearing or provisioning young, and so are less restricted to those areas with the highest concentrations of prey and water. Instead, they can cover a more extensive territory in search of mates and resources. Females, however, must stay near their young to feed and protect them. Consequently, female home ranges prefer those areas with the highest prey densities and most abundant water supplies, found primarily in the floodplain zone.

Additionally, unlike males, whose home ranges overlap those of several females, female home ranges are smaller and generally do not overlap with other females. This difference in mobility between the sexes is evident in our data when the number of individual males identified in our study, 16, is compared to the total number of different locations recorded, 57 . In contrast, the 41 female individuals were recorded at only 69 different locations.

Our sex-specific Maxent models also highlighted the aversion of female tigers to Sal forests, where there is sparse understory vegetation. These results suggest a female's preference for vegetation with a dense understory, such as grassland and riverine forest. Studies recording females giving birth in tall grass, thick brush, under fallen trees, or beneath rocks [30] show that females may be avoiding Sal forest due to its inability to conceal vulnerable cubs, which remain in these locations for up to a month. Afterward, they frequently move between such sites throughout the female's home range. As the sole caretakers of offspring, such areas are critical for female tigers. Our male Maxent model showed no such preference regarding vegetation type, although the male occupancy model showed a strong preference for avoiding Sal forests.

Importantly, our models also showed differences among male and female tigers toward areas closer to human settlements, that male tigers appear less averse to human disturbance. While the mutual attraction of tigers and humans to the floodplain area of CNP may account for a portion of this effect, earlier studies [26,47] suggest that current rates of grass burning and cutting and the occasional grazing of livestock may produce habitats that attract large ungulates, thereby increasing prey abundance. Furthermore, livestock depredation by tigers is well documented within CNP and similar areas, where tiger habitat borders agricultural settlements [20,48,49]. In Bardia National Park, Nepal, Bhattarai (2014) found tigers responsible for a total mean loss of livestock within adjacent communities of 0.75 head per household per year.

Although the model outputs suggested that female tigers show specific aversions to human settlements, this aversion is not uniform, as the suitability habitat map indicates that much of the community forest close to the boundaries overlaps with female tiger habitats (Figure 3). This study identified several critical concerns for tiger conservation at the socio-ecological interface. For example, though tigers breed year-round, breeding is most frequent between November and April, and efforts to shift potentially disruptive practices such as grass-cutting and fuelwood collection could avoid critical female habitat during times of the year when young cubs are most vulnerable, roughly 100 days after breeding [30]. Anti-poaching measures designed to protect prey species can also be focused on these areas, as prey depletion reduces carrying capacity for female tigers as well as cub survivorship [50]. Studies suggest such measures may also help address a significant source of human-tiger conflict: livestock depredation, which is significantly lower than average in areas with higher natural prey abundance [48] a trend that is positively related to national park frontage [49].

Though no consensus has been reached on the use of AUC as a performance measure for habitat suitability models, they are typically evaluated as 'good' if AUC is more significant than 0.7 [38]. While all our models provided statistically significant predictive power, only our female Maxent and occupancy model had a test AUC above 0.7. When a species is more widespread and the study area is small, well-predicted absences are minimized, 
resulting in lower AUC scores [36,38,39]. As our study area encompasses areas where tigers exist at some of the world's highest densities, the three Maxent modeled populations are considered widespread. Evidence of this effect can be seen most clearly in our male-only model, which found that suitable habitat was more widespread and occurred in a more heterogeneous environmental background than for females.

Imperfect detection of a species can also negatively affect the performance of habitat models. Suitability estimates may be biased if the locations of presences and absences result from detecting a species rather than habitat suitability. Our results also highlighted the importance of model selection by comparing Maxent and occupancy models, as the models yielded different predictions on the landscape. After including imperfect detection into our model estimates, we find a much broader classification for tigers throughout the park than Maxent, showing the most restricted range in the female population. The ability of occupancy models to fit the data was similar to Maxent in our case, showing similar AUC scores, indicating the models fit marginally. Because Maxent models presence data only while ignoring absences [35], it addresses this bias to some degree. Rota et al. (2011) concluded that occupancy modeling, which accounts for detection probability, showed only modest improvements in predictive performance over Maxent and that these improvements declined as detection probability declined, suggesting that Maxent may indeed perform well when detection probabilities are low. Furthermore, Lahoz-Monfort et al. (2014) suggest that if detection probability is relatively constant throughout a study site, Maxent's ability to identify suitable habitats is not impaired [51].

Previous occupancy modeling defined sex-indiscriminate fine-scale habitat selection of tigers in Chitwan National Park, mainly based on areas with a high prey, low slope, and relatively close proximity to human settlements; although, mainly defining tiger use habitat as a generalist [17]. The present study sought to extend this work to sex-specific modeling to understand where priority areas may exist where the species may respond to landscape covariates differentially between sexes, finding that males are much more likely to prefer riverine areas.

Spatial capture-recapture has been used to identify areas of higher tiger density, creating spatially explicit maps within the Chitwan National Park [26,52] and specifically within the Churia Hills area of the park [18]. Our study complemented this research by providing MaxEnt and Occupancy resource selection maps for males and females independently. However, future studies may seek to quantify sex-specific tiger densities at a fine-scale using models produced by previous studies that use the sex structure included for the baseline encounter and the sigma space use parameters to garner improved estimates for total density $[53,54]$. A study dedicated explicitly to sex-specific spatial capture-recapture in the context of separately quantifying density for males and density for females on the landscape would be an exciting application of these data in addition to adding sex parameters to a sex-indiscriminate model if done thoroughly.

One relationship we could not explore in this study was the effect of roads on tiger habitat selection [55]. Although research on tigers and other large felids has shown that distance to roads affects the movement and distribution of males and females differently [13], previous research within CNP suggests their effects on habitat suitability to be minimal. A visual inspection of tiger presence records across the study area shows that most occurrences for all modeled populations are in areas with denser road networks compared to areas with fewer records of tiger presence. Despite excluding roads as a predictive variable, there is evidence, both anecdotal and empirical, to suggest that their effect on tiger presence may be minimal. However, for this study, comprehensive fine-scale road data were unobtainable for several reasons: (1) no up-to-date GIS road data for the study area were known to exist prior to the analysis; (2) due to the relatively low spatial resolution of the imagery available $(30 \mathrm{~m})$ for the land cover classification, only the widest roads within the study area were detectable during image classification; (3) the structure of the vegetation throughout the study site obscured ground visibility (nearly $70 \%$ is covered by closed-canopy forest), making manual digitizing of roads problematic; and (4) because 
road data are often a proxy for human/vehicular activity, and because many of the area's roads are vestiges of prior, now removed settlements within the park, whether or not a road was still in use was impossible to determine. Carter et al., (2012) found that Chitwan's tigers, though warier near human settlement, nonetheless co-occurred at fine spatial scales with levels of human and traffic activity several orders of magnitude higher than those found in most other tiger-occupied landscapes. Their study showed that tigers shifted their activities temporally to coincide with times when humans were less active, instead of avoiding these areas entirely.

\section{Conclusions}

We have identified significant differences between male and female tiger habitat selection by creating sex-specific habitat models. This finding has implications for other carnivore species, which have suffered population extinctions in the past two centuries due to high human population densities, intensive land use activities, (e.g., agriculture, grazing and hunting), and subsequent loss and fragmentation of these habitats $[7,8]$. Underestimating human-induced habitat loss due to knowledge or analytical gaps can have substantial conservation ramifications [7]. Our results corroborate this finding and suggest that one way to reduce this risk is through sex-specific habitat modeling. Our models have shown that female tigers restrict their distribution to a much smaller geographic area than males, and prefer higher prey abundances.

Furthermore, suitable habitats for female tigers were confined almost entirely to the CNP floodplain region and showed a strong aversion to the Sal forest. On the other hand, males inhabited a much broader part of the study area and showed no preference for or aversion to any vegetation type. Disregarding these sex-related differences in habitat selection would yield an overly optimistic estimate of suitable habitat range for tigers, especially female tigers.

These findings have important implications for future management regimes at CNP and other tiger-occupied landscapes. Surprisingly, the occupancy model predicted that tigers could potentially occupy $80 \%$ of the park. The full Maxent model was more similar to the female model. Overall, identifying the areas most suitable for breeding females allows for more effective coordination of potentially disruptive practices within CNP and its buffer zone and better resource allocation dedicated to curtailing the illegal poaching of tigers and their prey species.

These allocations are significant when people and wildlife compete for space and/or resources, and managers should set up appropriate times and places where humans can conduct some disruptive activities while minimizing their impact on large carnivores. For instance, CNP allows a time window of three to five days when local villagers can go into the CNP core zone for grass collection in limited areas, and different buffer zone community forests open for a short period for grass, fuelwood, and fodder collection [56]. The time window and the locations of permitted disruptive activities can consider tiger habitat selection needs more scientifically in order to minimize negative impacts on tigers and alleviate human-tiger conflict.

Our research points to a need for extensive carnivore management to garner broader biodiversity and the enormous social and economic benefits [8]. Like tigers, male and female carnivores of other species may also have quite different habitat requirements and, therefore, spatial distributions; ignoring or downplaying such differences may reduce or lose conservation efficacy. Instead, it is crucially important to identify the set of 'bottlenecks', limiting factors that determine females' habitat selection, offering best-practice guidelines for management purposes. All these efforts may operationalize the so-called 'novel, bold, and deliberate actions' [8] to protect the large carnivores that deliver irreplaceable ecological function and services worldwide, contributing directly or indirectly to Goal 15 (life on land) of the United Nations' 17 Sustainable Development Goals [57].

Author Contributions: Conceptualization L.A.; Methodology, Formal Analysis, E.B., C.B. and J.D.; Writing-Review \& Editing, R.L., P.J., N.C. and A.Z.; Supervision, Data Curation, and Project 
Administration, D.G., M.D. and J.K. All authors have read and agreed to the published version of the manuscript.

Funding: The National Science Foundation-funded this research under the Dynamics of Coupled Natural and Human Systems program [DEB-1212183, BCS-1826839, BCS-1211498] and the Partnership for International Research and Education (OISE 0729709). This research also received financial and research support from San Diego State University.

Institutional Review Board Statement: The study was conducted according to the guidelines of the National Trust for Nature Conservation and the Government of Nepal.

Informed Consent Statement: Not applicable.

Data Availability Statement: The data presented in this study are available on request from the corresponding author. The data are not publicly available due to being highly sensitive and requiring permission.

Acknowledgments: We would like to thank the NSF and Partnership for International Research and Education for generous funding opportunities making this work possible.

Conflicts of Interest: The authors declare no conflict of interest.

\section{References}

1. Schipper, J.; Chanson, J.S.; Chiozza, F.; Cox, N.A.; Hoffmann, M.; Katariya, V.; Lamoreux, J.; Rodrigues, A.S.L.; Stuart, S.N.; Temple, H.J.; et al. The Status of the World's Land and Marine Mammals: Diversity, Threat, and Knowledge. Science 2008, 322, 225-230. [CrossRef]

2. Hoffmann, M.; Belant, J.L.; Chanson, J.S.; Cox, N.A.; Lamoreux, J.; Rodrigues, A.S.L.; Schipper, J.; Stuart, S.N. The Changing Fates of the World's Mammals. Philos. Trans. R. Soc. B Biol. Sci. 2011, 366, 2598-2610. [CrossRef] [PubMed]

3. Ripple, W.J.; Estes, J.A.; Beschta, R.L.; Wilmers, C.C.; Ritchie, E.G.; Hebblewhite, M.; Berger, J.; Elmhagen, B.; Letnic, M.; Nelson, M.P.; et al. Status and Ecological Effects of the World's Largest Carnivores. Science 2014, 343, 1241484. [CrossRef] [PubMed]

4. Ripple, W.J.; Wolf, C.; Newsome, T.M.; Hoffmann, M.; Wirsing, A.J.; McCauley, D.J. Extinction Risk Is Most Acute for the World's Largest and Smallest Vertebrates. Proc. Natl. Acad. Sci. 2017, 114, 10678-10683. [CrossRef]

5. Rodrigues, A.S.; Brooks, T.M.; Butchart, S.H.; Chanson, J.; Cox, N.; Hoffmann, M.; Stuart, S.N. Spatially Explicit Trends in the Global Conservation Status of Vertebrates. PLoS One 2014, 9, e113934. [CrossRef]

6. Villard, M.-A.; Trzcinski, M.K.; Merriam, G. Fragmentation Effects on Forest Birds: Relative Influence of Woodland Cover and Configuration on Landscape Occupancy. Conserv. Biol. 1999, 13, 774-783. [CrossRef]

7. Ceballos, G.; Ehrlich, P.R. Mammal Population Losses and the Extinction Crisis. Science 2002, 296, 5. [CrossRef] [PubMed]

8. Ripple, W.J.; Chapron, G.; López-Bao, J.V.; Durant, S.M.; Macdonald, D.W.; Lindsey, P.A.; Bennett, E.L.; Beschta, R.L.; Bruskotter, J.T.; Campos-Arceiz, A.; et al. Saving the World's Terrestrial Megafauna. BioScience 2016, 66, 807-812. [CrossRef] [PubMed]

9. WWF. WWF Global Wild Tiger Population Status; Technical Report; WWF: Gland, Switzerland, 2016.

10. Sanderson, E.W.; Forrest, J.; Loucks, C.; Ginsberg, J.; Dinerstein, E.; Seidensticker, J.; Leimgruber, P.; Songer, M.; Heydlauff, A.; O'Brien, T.; et al. Setting Priorities for Tiger Conservation. In Tigers of the World; Elsevier: Amsterdam, The Netherlands, 2010; pp. 143-161. ISBN 978-0-8155-1570-8.

11. Broomhall, L.S.; Mills, M.G.L.; Toit, J.T. Home Range and Habitat Use by Cheetahs ( Acinonyx Jubatus ) in the Kruger National Park. J. Zool. 2003, 261, 119-128. [CrossRef]

12. Gaines, W.L.; Lyons, A.L.; Lehmkuhl, J.F.; Raedeke, K.J. Landscape Evaluation of Female Black Bear Habitat Effectiveness and Capability in the North Cascades, Washington. Biol. Conserv. 2005, 125, 411-425. [CrossRef]

13. Conde, D.A.; Colchero, F.; Zarza, H.; Christensen, N.L.; Sexton, J.O.; Manterola, C.; Chávez, C.; Rivera, A.; Azuara, D.; Ceballos, G. Sex Matters: Modeling Male and Female Habitat Differences for Jaguar Conservation. Biol. Conserv. 2010, 143, 1980-1988. [CrossRef]

14. Carter, N. Modeling Tiger Population and Territory Dynamics Using an Agent-Based Approach. Ecol. Model. 2015, 16, 347-362. [CrossRef]

15. Carter, N.H.; Levin, S.A.; Grimm, V. Effects of Human-induced Prey Depletion on Large Carnivores in Protected Areas: Lessons from Modeling Tiger Populations in Stylized Spatial Scenarios. Ecol. Evol. 2019, 9, 11298-11313. [CrossRef]

16. Rayan, D.M.; Linkie, M. Managing Conservation Flagship Species in Competition: Tiger, Leopard and Dhole in Malaysia. Biol. Conserv. 2016, 204, 360-366. [CrossRef]

17. Kafley, H.; Gompper, M.E.; Sharma, M.; Lamichane, B.R.; Maharjan, R. Tigers (Panthera Tigris) Respond to Fine Spatial-Scale Habitat Factors: Occupancy-Based Habitat Association of Tigers in Chitwan National Park, Nepal. Wildl. Res. 2016, 43, 398. [CrossRef]

18. Thapa, K.; Kelly, M.J. Density and Carrying Capacity in the Forgotten Tigerland: Tigers in the Understudied Nepalese Churia. Integr. Zool. 2017, 12, 211-227. [CrossRef] 
19. Carter, N.H.; Shrestha, B.K.; Karki, J.B.; Pradhan, N.M.B.; Liu, J. Coexistence between Wildlife and Humans at Fine Spatial Scales. Proc. Natl. Acad. Sci. 2012, 109, 15360-15365. [CrossRef] [PubMed]

20. Stræde, S.; Helles, F. Park-People Conflict Resolution in Royal Chitwan National Park, Nepal: Buying Time at High Cost? Environ. Conserv. 2000, 27, 368-381. [CrossRef]

21. WWF. The Terai Arc Landscape: Bengal Tigers in the Himalaya's Shadow; Technical Report; WWF: Gland, Switzerland, 2004.

22. Carter, N.H.; Gurung, B.; Viña, A.; Campa III, H.; Karki, J.B.; Liu, J. Assessing Spatiotemporal Changes in Tiger Habitat across Different Land Management Regimes. Ecosphere 2013, 4, art124. [CrossRef]

23. GoN Tiger Conservation Action Plan for Nepal, Kathmandu; Technical Report; Government of Nepal: Kathmandu, Nepal, 2008.

24. Thapa, T.B. Habitat Suitability Evaluation for Leopard (Panthera Pardus) Using Remote Sensing and GIS in and around Chitwan National Park, Nepal; Saurashtra University: Rajkot, India, 2011.

25. Chanchani, P.; Lamichhane, B.R.; Malla, S.; Maurya, K.; Bista, A.; Warrier, R.; Nair, S.; Almeida, M.; Ravi, R.; Sharma, R.; et al. Tigers of the Transboundary Terai Arc Landscape Status, Distribution and Movement in the Terai of India and Nepal; Global Tiger Forum: Dew Delhi, India, 2014. [CrossRef]

26. Karki, J.B.; Pandav, B.; Jnawali, S.R.; Shrestha, R.; Pradhan, N.M.B.; Lamichane, B.R.; Khanal, P.; Subedi, N.; Jhala, Y.V. Estimating the Abundance of Nepal's Largest Population of Tigers Panthera Tigris. Oryx 2015, 49, 150-156. [CrossRef]

27. Ahearn, S.C.; Smith, J.L.D.; Joshi, A.R.; Ding, J. TIGMOD: An Individual-Based Spatially Explicit Model for Simulating Tiger/Human Interaction in Multiple Use Forests. Ecol. Model. 2001, 140, 81-97. [CrossRef]

28. Smith, J.L.D. The Role of Dispersal in Structuring the Chitwan Tiger Population. Behaviour 1993, 124, 165-195. [CrossRef]

29. Kanagaraj, R.; Wiegand, T.; Kramer-Schadt, S.; Anwar, M.; Goyal, S.P. Assessing Habitat Suitability for Tiger in the Fragmented Terai Arc Landscape of India and Nepal. Ecography 2011, 34, 970-981. [CrossRef]

30. Mazak, V. Panthera Tigris. In The American Society of Mammologists; 1981; Volume 152, pp. 1-8.

31. Phillips, S.J.; Anderson, R.P.; Schapire, R.E. Maximum Entropy Modeling of Species Geographic Distributions. Ecol. Model. 2006, 190, 231-259. [CrossRef]

32. MacKenzie, D.I.; Nichols, J.D.; Hines, J.E.; Knutson, M.G.; Franklin, A.B. Estimating Site Occupancy, Colonization, and Local Extinction When a Species Is Detected Imperfectly. Ecology 2003, 84, 2200-2207. [CrossRef]

33. Elith, J.; Graham, C.H. Do They? How Do They? WHY Do They Differ? On Finding Reasons for Differing Performances of Species Distribution Models. Ecography 2009, 32, 66-77. [CrossRef]

34. Elith, J.; Phillips, S.J.; Hastie, T.; Dudík, M.; Chee, Y.E.; Yates, C.J. A Statistical Explanation of MaxEnt for Ecologists: Statistical Explanation of MaxEnt. Divers. Distrib. 2011, 17, 43-57. [CrossRef]

35. Elith, J.; Graham, C.H.; Anderson, R.P.; Dudík, M.; Ferrier, S.; Guisan, A.; Hijmans, R.J.; Huettmann, F.; Leathwick, J.R.; Lehmann, A.; et al. Novel Methods Improve Prediction of Species' Distributions from Occurrence Data. Ecography 2006, 29, 129-151. [CrossRef]

36. Hernandez, P.A.; Graham, C.H.; Master, L.L.; Albert, D.L. The Effect of Sample Size and Species Characteristics on Performance of Different Species Distribution Modeling Methods. Ecography 2006, 29, 773-785. [CrossRef]

37. Rupprecht, F.; Oldeland, J.; Finckh, M. Modelling Potential Distribution of the Threatened Tree Species Juniperus Oxycedrus: How to Evaluate the Predictions of Different Modelling Approaches?: Modelling Potential Distribution of Juniperus Oxycedrus. J. Veg. Sci. 2011, 22, 647-659. [CrossRef]

38. Lobo, J.M.; Jiménez-Valverde, A.; Real, R. AUC: A Misleading Measure of the Performance of Predictive Distribution Models. Glob. Ecol. Biogeogr. 2008, 17, 145-151. [CrossRef]

39. McPherson, J.M.; Jetz, W. Effects of Species' Ecology on the Accuracy of Distribution Models. Ecography 2007, 30, 135-151. [CrossRef]

40. Raes, N.; ter Steege, H. A Null-Model for Significance Testing of Presence-Only Species Distribution Models. Ecography 2007, 30, 727-736. [CrossRef]

41. MacKenzie, D.I.; Bailey, L.L.; Nichols, J.D. Investigating Species Co-Occurrence Patterns When Species Are Detected Imperfectly. J. Anim. Ecol. 2004, 73, 546-555. [CrossRef]

42. Royle, J.A.; Kery, M. Applied Hierarchical Modeling in Ecology: Analysis of Distribution, Abundance and Species Richness in R and BUGS; Volume 1: Prelude and Static Models; Elsevier: Amsterdam, The Netherlands, 2015.

43. Kellner, K. Package "JagsUI." CRAN Repos. 2019. Available online: https://cran.r-project.org/web/packages/jagsUI/jagsUI.pdf (accessed on 15 November 2021).

44. Broms, K.M.; Hooten, M.B.; Fitzpatrick, R.M. Model Selection and Assessment for Multi-Species Occupancy Models. Ecology 2016, 97, 1759-1770. [CrossRef]

45. Majka, D.; Jenness, J.; Beier, P. CorridorDesigner: ArcGIS Tools for Designing and Evaluating Corridors. 2007. Available online: https:/ / corridordesign.org/ (accessed on 15 November 2021).

46. Smith, J.L.D.; McDougal, M.; Sunquist, M.E. Female Land Tenure System in Tigers. In Tigers of the World: The Biology, Biopolitics, Management, and Conservation of an Endangered Species.; Noyes Publications: Park Ridge, IL, USA, 1987; p. 510.

47. Karki, J.B.; Jnwali, S.R.; Shrestha, R.; Pandey, M.B.; Gurung, G.; Thapa, M. Tiger and Their Prey Base Abundance in Terai Arc Landscape Nepal; Ministry of Forests and Soil Conservation Department of National Parks and Wildlife Conservation and Department of Forests: Babar Mahal, Nepal, 2009. 
48. Bhattarai, B.R.; Fischer, K. Human-Tiger Panthera Tigris Conflict and Its Perception in Bardia National Park, Nepal. Oryx 2014, 48, 522-528. [CrossRef]

49. Dhungana, R. Human-Tiger (Panthera Tigris Tigris) Conflict in Chitwan National Park, Nepal. Master's Thesis, Prince of Songkla University, Hat Yai, Thailand, 2016.

50. Karanth, K.; Stith, B. Prey Depletion Is a Critical Determinant of Tiger Population Viability. In Riding the Tiger: Tiger Conservation in Human-Dominated Landscapes; Cambridge University Press: Cambridge, UK, 1999; pp. 100-113.

51. Lahoz-Monfort, J.J.; Guillera-Arroita, G.; Wintle, B.A. Imperfect Detection Impacts the Performance of Species Distribution Models. Glob. Ecol. Biogeogr. 2014, 23, 504-515. [CrossRef]

52. Lamichhane, B.R.; Leirs, H.; Persoon, G.A.; Subedi, N.; Dhakal, M.; Oli, B.N.; Reynaert, S.; Sluydts, V.; Pokheral, C.P.; Poudyal, L.P.; et al. Factors Associated with Co-Occurrence of Large Carnivores in a Human-Dominated Landscape. Biodivers. Conserv. 2019, 28, 1473-1491. [CrossRef]

53. Sollmann, R.; Furtado, M.M.; Gardner, B.; Hofer, H.; Jácomo, A.T.A.; Tôrres, N.M.; Silveira, L. Improving Density Estimates for Elusive Carnivores: Accounting for Sex-Specific Detection and Movements Using Spatial Capture-Recapture Models for Jaguars in Central Brazil. Biol. Conserv. 2011, 144, 1017-1024. [CrossRef]

54. Satter, C.B.; Augustine, B.C.; Harmsen, B.J.; Foster, R.J.; Kelly, M.J. Sex-specific Population Dynamics of Ocelots in Belize Using Open Population Spatial Capture-Recapture. Ecosphere 2019, 10, e02792. [CrossRef]

55. Carter, N.; Killion, A.; Easter, T.; Brandt, J.; Ford, A. Road Development in Asia: Assessing the Range-Wide Risks to Tigers. Sci. Adv. 2020, 6, eaaz9619. [CrossRef] [PubMed]

56. Jones, S. Tigers, Trees and Tharu: An Analysis of Community Forestry in the Buffer Zone of the Royal Chitwan National Park, Nepal. Geoforum 2007, 38, 558-575. [CrossRef]

57. Diaz, S. Summary for Policymakers of the Global Assessment Report on Biodiversity and Ecosystem Services of the Intergovernmental Science-Policy Platform on Biodiversity and Ecosystem Services; IPBES Secretariat: Bonn, Germany, 2019. 